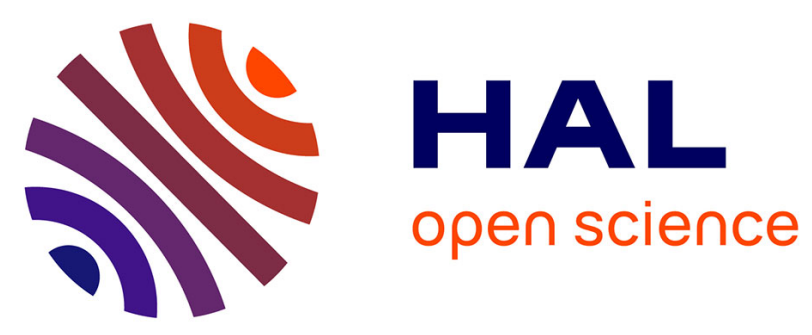

\title{
A Passive Pressure Sensor for Continuously Measuring the Intraocular Pressure in Glaucomatous Patients
} Philippe Auvray, Lionel Rousseau, Gaelle Bazin Lissorgues, Fabien Soulier, Olivier Potin, Serge Bernard, François Dieuleveult, Emmanuel Scorsone, Philippe Bergonzo, Laurent Chicaud, et al.

\section{To cite this version:}

Philippe Auvray, Lionel Rousseau, Gaelle Bazin Lissorgues, Fabien Soulier, Olivier Potin, et al.. A Passive Pressure Sensor for Continuously Measuring the Intraocular Pressure in Glaucomatous Patients. Innovation and Research in BioMedical engineering, 2012, Numéro spécial ANR TECSAN

- Technologie pour la santé et l'autonomie, 33 (2), pp.117-122. 10.1016/j.irbm.2012.01.002 lirmm00685354

\section{HAL Id: lirmm-00685354 https://hal-lirmm.ccsd.cnrs.fr/lirmm-00685354}

Submitted on 23 Mar 2020

HAL is a multi-disciplinary open access archive for the deposit and dissemination of scientific research documents, whether they are published or not. The documents may come from teaching and research institutions in France or abroad, or from public or private research centers.
L'archive ouverte pluridisciplinaire HAL, est destinée au dépôt et à la diffusion de documents scientifiques de niveau recherche, publiés ou non, émanant des établissements d'enseignement et de recherche français ou étrangers, des laboratoires publics ou privés. 
Elsevier Editorial System(tm) for IRBM, Ingénierie et Recherche Biomédicale / IRBM BioMedical Engineering and Research Manuscript Draft

Manuscript Number: IRBM-D-12-00011

Title: A passive pressure sensor for continuously measuring the intraocular pressure in glaucomatous patients

Article Type: ANR TecSAN 2008

Keywords: Medical device, Sensor, Glaucoma, Pressure, Ophthalmology

Corresponding Author: Dr. serge picaud,

Corresponding Author's Institution: INSERM/UPMC

First Author: philippe auvray

Order of Authors: philippe auvray; lionel rousseau; gaelle lissorgues; fabien soulier; olivier potin; serge bernard; francois de dieuleveult; emmanuel scorsone; philippe bergonzo; laurent chicaud; serge picaud; jose alain sahel

Abstract: Objective: The main risk factor for the development of glaucoma, a retinal disease leading to blindness, is an increase in the intraocular pressure (IOP). Reducing this IOP can be obtained by eye drops but unfortunately the disease can still progress because IOP increases are painless, can fluctuate and, thus remain undetected during a visit to an ophthalmologist. The "MATEO" ANR project aims to develop sensors embedded in a contact lens for continuously IOP monitoring.

Materials and methods: Pressure sensors were produced by MEMS technology and tested with pig eyes obtained at a local slaughterhouse. Solution was injected by $50 \mu \mathrm{L}$ steps in the eye with a Hamilton syringe while IOP was monitored in parallel with a TonoVET system and an industrial pressure transducer inserted in the injection tubing system.

Results: Our first pressure sensor prototypes were generated and inserted in a lens compatible with eye application. A wireless system was developed to excite the sensor. At same time, it was recorded the data in components inserted into spectacles and a pocket recorder. In parallel, we showed that injecting a solution in the eye anterior chamber triggered an IOP increase smaller and more stable than injections in the posterior chamber. Finally, a direct correlation was observed between IOP measured on the corneal surface with the TonoVET and the pressure transducer placed close to eye injection point.

Discussion: Our results indicate that our in vitro model on pig eyes is adequate to test our new lens sensor. Finally, the pressure sensor was successfully inserted in contact lens opening the way for their in-vitro and in-vivo preclinical validation.

Suggested Reviewers: alain bron alain.bron@chu-dijon.fr ophtalmologist 
A passive pressure sensor for continuously measuring the intraocular pressure in glaucomatous patients

by

P. Auvray ${ }^{1}$, L. Rousseau ${ }^{2}$, G. Lissorgues ${ }^{2}$, F. Soulier ${ }^{3}$, O. Potin ${ }^{3}$, S. Bernard ${ }^{3}$, F.

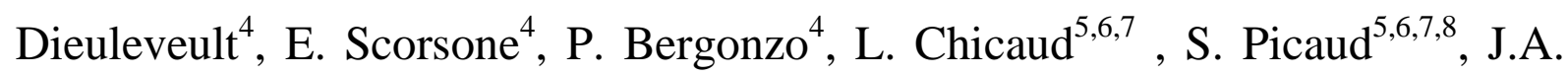
Sahel ${ }^{5,6,7,8,9,10}$

${ }^{1}$ OPHTIMALIA, Paris, France.

${ }^{2}$ ESIEE - ESYCOM University Paris Est, Cité Descartes, BP99, 93162 Noisy Le Grand, France.

${ }^{3}$ LIRMM, UMR 5506 - CC 477, Université Montpellier II, Montpellier, France.

${ }^{4}$ CEA, LIST, Diamond Sensor Laboratory, CEA/Saclay, Gif-sur-Yvette, France.

${ }^{5}$ INSERM, U968, Institut de la Vision, Paris, F-75012, France.

${ }^{6}$ UPMC Univ Paris 06, UMR_S968, Institut de la Vision, Paris, F-75012, France.

${ }^{7}$ CNRS, UMR 7210, Institut de la Vision, Paris, F-75012, France.

${ }^{8}$ Fondation Ophtalmologique Adolphe de Rothschild, Paris, France.

${ }^{9}$ Centre Hospitalier National d'Ophtalmologie des Quinze-Vingts, Paris, France.

${ }^{10}$ Institute of Ophthalmology, University College of London, UK.

\section{Corresponding author:}

Dr. Serge Picaud

Institut de la Vision

17, rue Moreau

75012 PARIS

France

Phone : (33) 153462592

Fax : (33) 153462601

E-mail : serge.picaud@inserm.fr 


\begin{abstract}
Objective: The main risk factor for the development of glaucoma, a retinal disease leading to blindness, is an increase in the intraocular pressure (IOP). Reducing this IOP can be obtained by eye drops but unfortunately the disease can still progress because IOP increases are painless, can fluctuate and, thus remain undetected during a visit to an ophthalmologist. The "MATEO" ANR project aims to develop sensors embedded in a contact lens for continuously IOP monitoring.
\end{abstract}

Materials and methods: Pressure sensors were produced by MEMS technology and tested with pig eyes obtained at a local slaughterhouse. Solution was injected by $50 \mu \mathrm{L}$ steps in the eye with a Hamilton syringe while IOP was monitored in parallel with a TonoVET system and an industrial pressure transducer inserted in the injection tubing system.

Results: Our first pressure sensor prototypes were generated and inserted in a lens compatible with eye application. A wireless system was developed to excite the sensor. At same time, it was recorded the data in components inserted into spectacles and a pocket recorder. In parallel, we showed that injecting a solution in the eye anterior chamber triggered an IOP increase smaller and more stable than injections in the posterior chamber. Finally, a direct correlation was observed between IOP measured on the corneal surface with the TonoVET and the pressure transducer placed close to eye injection point.

Discussion: Our results indicate that our in vitro model on pig eyes is adequate to test our new lens sensor. Finally, the pressure sensor was successfully inserted in contact lens opening the way for their in-vitro and in-vivo preclinical validation.

Keywords — Medical device, Sensor, Glaucoma, Pressure, Ophthalmology

\title{
Résumé
}

Objectifs: L'augmentation de pression intraoculaire (PIO) est le principal facteur de risque du glaucome - une pathologie cécitante. Bien qu'une réduction de la PIO puisse être obtenue par des gouttes oculaires, la maladie peut tout de même progresser car l'augmentation de PIO est indolore, fluctue dans le temps et par conséquent reste indétectable à l'examen ophtalmologique. Le projet ANR "MATEO" vise à produire des capteurs intégrés dans des lentilles de contact pour mesurer en continu la PIO.

Matériels et méthodes : Des capteurs de pression ont été produits par la technologie MEMS et testés sur des yeux de porc obtenus à un abattoir local. Une solution a été injectée dans l'œil par dose de $50 \mu \mathrm{L}$ grâce à une seringue Hamilton pendant que la PIO était mesurée en parallèle avec un TonoVET et un capteur (transducteur) de pression industriel, inséré dans le dispositif d'injection.

Résultats: Nos prototypes de capteurs de pression ont été intégrés avec succès dans des lentilles compatibles avec l'œil. Un système électronique sans fil embarqué sur une lunette a été développé pour exciter le capteur et enregistrer des données image de la PIO. Parallèlement, nous avons montré que l'injection d'une solution dans la chambre antérieure de 
l'œil produit une augmentation de PIO plus faible et plus stable que les injections dans la chambre postérieure. Enfin, nous avons observé une corrélation directe entre la PIO mesurée sur la surface cornéenne avec le TonoVET et le capteur de pression placé prêt du point d'injection sur l'œil.

Discussion : Nos résultats montrent que notre modèle in vitro sur l'œil de porc est adapté pour tester le nouveau capteur de PIO. Ce capteur de pression a été inséré avec succès dans une lentille ouvrant ainsi la voie à sa validation préclinique in vitro et in vivo.

Mots clés-Dispositif médical, Capteur, Pression, Glaucome, Ophtalmologie 


\section{Introduction}

Glaucoma affects 1 in 100 individuals of those over 40-50 years old, which represents 60 million people worldwide. According to the World Health Organization, the number of glaucomatous patients will increase to 80 million people worldwide in 2020. Open angle glaucoma represents $12 \%$ of registered legal blindness in the USA and Great Britain. A retrospective study carried out over 15 years, shows that patients affected by this type of glaucoma lose sight in both eyes in $9 \%$ of cases, and in one eye in $26 \%$ of cases [1]. This widespread disease is characterized by a gradual and irreversible loss of peripheral visual field with associated optic nerve cupping. In fact, this type of blindness results from the degeneration of retinal ganglion cells that project their axon onto the brain via the optic nerve. In the UK, the cost of glaucoma is estimated at $£ 300$ millions.

In the case of open angle glaucoma, apart from age and family history of glaucoma, the main risk factor is higher intraocular pressure (IOP) [2]. Reducing this intraocular pressure is now possible with eye drops containing different pharmacological agents and it was demonstrated to greatly reduce the risk of developing the visual loss [3]. Different hypotheses have been proposed to explain the IOP-elicited degenerative process of retinal ganglion cells including a decreased blood perfusion resulting in retinal and optic nerve ischemia [4].

To prevent the disease and its progression, it is therefore a great medical need to monitor the patient IOP. Today, applanation tonometry, most often performed with the Goldmann applanation tonometer, has become the standard procedure for measuring IOP. The Goldmann method was considered the most accurate and precise by $99 \%$ of the ophthalmologists who answered the survey. While it can measure IOP at a given time during a visit to an ophthalmologist, applanation tonometry cannot monitor variations over time at different periods of the day, which is its main limitation. Currently, the only way to obtain data on the daily IOP evolution, to improve diagnosis and management of glaucoma, is to repeat such measurements many times a day, although it provides only a rough estimation and is a very cumbersome procedure for the patients, who have to stay at hospital or come back many times in a day. A recent study has shown that 24-hour IOP monitoring results in a change in clinical management of glaucoma in $79.3 \%$ of patients [5]. Therefore, researchers and clinicians in the field recognize the urgent need for an improved diagnostic tool capable of continuously monitoring the IOP. Such a continuous monitoring would not only improve diagnostic but also it would facilitate drug testing for IOP lowering.

Because standard clinic follow-up evaluations fail to identify peaks and IOP variations, many attempts to find a practical and portable solution for monitoring IOP have been made without success. Recently, a device has been commercialized by a Swiss company "Sensimed" and is based on a contact lens integrating a strain gauge controlled by a transceiver, integrated in a contact lens. This wireless device needs to integrate a complex 
and costly technology into a rather thick contact lens, which may explain the reported corneal abrasion and intolerance [6-7-8].

In the present MATEO ANR project, named after a deceased student colleague, we suggest to embed a simpler IOP passive sensor in a thinner contact lens. This new device should enable clinicians to perform one measurement every 10 minutes, which is largely sufficient to monitor daytime variations or every 5 minutes on diagnostic mode to try to associate the relationship with the physical environment of the patient (posture, activity, environment, etc). It should allow a continuous and minimally invasive IOP monitoring over long periods, regardless of the patient's position and activities.

2. Description of the portable IOP monitoring device

a. Overview of the system

The key element of this innovative measurement method is a soft contact lens with an embedded passive sensor (LC type resonant circuitry). This sensor is an ultra-thin microfabricated sensor that allows the measurement of changes in cornea curvature correlated to IOP. This lens sensor is associated to portable components required to achieve measurements and store the data over the recording period.

Figure1 represents the three different components of the complete system:

- The soft contact lens with an integrated passive sensor, having its intrinsic characteristics modified by the intraocular pressure effects on cornea.

- A dedicated spectacle frame with embedded electronics to excite the sensor and transmit measurement data to a recorder.

- A recording device which accumulates measured data for further processing at the end of the monitoring.

Our aim is to generate a lens sensor as simple as possible because this part is a disposable component whereas all costly and complex signal processing circuits are integrated and spread between the spectacle frame and the pocket recorder because these two components will be reusable parts.

\section{b. Design based on a system-level approach}

Multiple and various factors co-exist and interact in the measurement process. The sensor structure must offer the maximum sensitivity because of small deformation of the cornea (a few tenths of microns). It should be coupled with the antenna on a small transparent and soft polymer lens. Finally, the signal processing functions have to deal with a 
composite signal degraded by strong interferences to extract the useful data and provide a reliable and accurate IOP variations measurement [IOP]. Unfortunately, it is impossible to optimize each part of the system independently. Indeed, by optimizing parameters of a part of the system, we might affect the efficiency of other parts of the system. For instance, to achieve a high variation of the electrical parameters "seen" by the spectacle frame, we need complex LC sensor but complex sensor will impact the rigidity of the lens and will decrease the sensitivity to corneal deformation.

In this context, a complete system modeling was developed (Fig.2), starting from the biomechanical characteristics of the eye to the electrical measurements and data estimation. This model allows us to play with the different trade-offs. Both mechanical and electrical aspects are covered in the model. Under magnetic coupling conditions, the eye mechanical modifications resulting from the IOP variations, transmitted to the sensor through the contact lens, can provide a detectable electrical parameter change (resonance frequency). Consequently, in this system, several successive transfer functions have to be defined to cover:

- the relation between IOP and corneal deformation

- the relation between corneal deformation and sensor deformation

- the relation between sensor deformation and electrical parameter variation

- the relation between electrical parameter variation and signal variation "seen" by the spectacle frame

- the signal processing for detection of signal variation in a noisy environment

- the algorithm for IOP-change estimation

As an illustration, the next sections explain the procedures used to establish some of these transfer functions.

c. Transfer function between IOP and corneal deformation

Some simulations were achieved to better understand the eye mechanical deformations under intraocular pressure variations and the effects on a sensor integrated into a soft contact lens.

d. Transfer function between sensor deformation and electrical parameter variation 
A dedicated microelectronic wafer fabrication process has been developed to fit with the optimum electrical requirements as well as mechanical considerations to ease the soft contact lens manufacturing.

Despite low emitted powers, an extensive screening of the allowed frequency domains has been achieved with RFID experts [9-10] and medical system EMC specialists. Two large domains have been identified, below $30 \mathrm{MHz}$ and in the neighborhood of $868 \mathrm{MHz}$. This has been deeply evaluated in terms of sensor size and process, complexity, sensitivity and robustness to interferers, both domains introducing a design complexity at a different place in the measurement chain.

e. Transfer function between electrical parameter variation and signal variation "seen" by the spectacle frame

The coupling conditions between the sensor (secondary) on contact lens and the antenna (primary) on spectacle frame described by Neumann equation are crucial for detecting these IOP variations and should be maximized.

Equation [1]

$$
M \stackrel{\Phi_{p s}}{I_{s}}=\frac{\mu_{0}}{4 \pi} \oint_{C_{p}} \oint_{C_{s}} \frac{\overrightarrow{d s_{p}} \overrightarrow{d s_{s}}}{\left|R_{p s}\right|}
$$

" $\mathrm{M}$ " is directly correlated to the surface of both primary and secondary loops $\left(\mathrm{C}_{\mathrm{p}} \mathrm{C}_{\mathrm{s}}\right)$ as well as the distance between these elements $\left(R_{p s}\right)$. Figure 5 represents a model for variation of the coupling coefficient under eye rotation effect, in case of two circular loop antennas.

The mutual inductance can in that case be simplified using the following relationship:

Equation [2]

$$
M=\frac{\mu_{\mathrm{o}}}{4 \pi} \iint_{0}^{2 \pi} \frac{\mathbf{X} . \mathbf{Y}}{\left|\mathbf{R}_{\mathrm{ps}}\right|} \text { with }
$$

$$
\begin{aligned}
& \overrightarrow{d s_{p} \leftrightarrow X}=\left[\begin{array}{c}
\rho_{\mathrm{p}} \cdot \sin \theta_{\mathrm{p}} \cdot\left(-\sin \varphi_{\mathrm{p}}\right) \mathrm{d} \varphi_{\mathrm{p}} \\
\rho_{\mathrm{p}} \cdot \sin \theta_{\mathrm{p}} \cdot\left(\cos \varphi_{\mathrm{s}}\right) \mathrm{d} \varphi_{\mathrm{p}} \\
0
\end{array}\right] \text { avec } \varphi_{\mathrm{p}}=[0.2 \pi] \\
& \overrightarrow{d s_{s} \Theta}=\left[\begin{array}{c}
\rho_{\mathrm{s}} \cdot \sin \theta_{\mathrm{s}} \cdot\left(-\sin \varphi_{\mathrm{s}}\right) \mathrm{d} \varphi_{\mathrm{s}} \\
\rho_{\mathrm{s}} \cdot \sin \theta_{\mathrm{s}} \cdot\left(\cos \varphi_{\mathrm{s}}\right) \mathrm{d} \varphi_{\mathrm{s}} \\
0
\end{array}\right] \text { avec } \varphi_{\mathrm{s}}=[0 \ldots 2 \pi]
\end{aligned}
$$

The passive sensor integrated in the contact lens is excited thanks to an electromagnetic field, generated by the primary antenna. Figure 6 represents the electrical model of the 
sensor-antenna sub-system [11], in which $\mathrm{L}_{\mathrm{s}}$ and $\mathrm{C}_{\mathrm{s}}$ are varying elements correlated to IOP variations. Any modification of the sensor parasitic capacitance (thus the resonance frequency) due to IOP variations is read out from the antenna (primary). The general relationship of the impedance seen from the primary is given by:

$$
\begin{aligned}
& \text { Equation [3] Z1 } \quad \text { [1. } L_{r} \omega .\left[1-k^{2} \frac{\left(j \frac{\omega}{\omega s}\right)^{2}}{1+j \cdot \frac{1}{Q s} \frac{\omega}{\omega s}+\left(j \frac{\omega}{\omega s}\right)^{2}}\right] \text { with } k=\mathbf{M} / \sqrt{ }\left(\mathbf{L}_{\mathbf{l}}(\mathbf{2} \cdot)\left(\mathbf{C}_{\downarrow} \mathbf{2}+\left(\mathbf{C}_{\mathbf{l}} \mathbf{t}\right)\right)\right. \text {, } \\
& Q_{s}=\frac{1}{\mathbf{R}_{2}} \sqrt{\frac{\mathbf{L}_{2}}{\left(\mathbf{C}_{2}+\mathbf{C}_{\mathrm{t}}\right)}} \text { and } \omega_{s}=\frac{1}{\sqrt{\mathbf{L}_{2 \cdot\left(\mathbf{C}_{2}+\mathbf{C}_{\mathrm{t}}\right)}}}
\end{aligned}
$$

With $k$ the coupling coefficient, $Q_{s}$ the sensor quality coefficient and $\omega_{s}=2^{*} \pi^{*} F_{s}$ the resonance pulsation.

A key part in the transfer function modeling is the development and correlation with glaucoma models elaborated on enucleated pig eyes.

\section{Glaucoma model on isolate pig eyes}

To assess the efficacy of our new lens sensor, we implemented an in vitro model of increase in IOP using isolated pig eyes obtained from a local slaughterhouse. The increase was obtained by repeated solution injections in the eye. These injections are achieved through a Hamilton micro syringe $(500 \mu \mathrm{L})$ controlled by a micro-injector and connected to the eye with a 23 gauge entry system, used in case of human surgeries (GA entry system enhanced ref : 8065751446, Alcon Laboratories).

Measurements of the eye IOP were performed using two independent reference systems. The first system - the TonoVET (Icare) - is classically used by veterinarians to measure IOP at the corneal surface. This TonoVET system relies on a probe power rebound onto the corneal surface to measure IOP requiring thereby a free access to the corneal surface. Therefore, these IOP measurements with the TonoVET are not possible when the sensor contact lens is placed on the pig eye cornea. The second system was therefore developed to continuously measure IOP even in the presence of the sensor contact lens. A pressure probe (PTX7500, General electric) was simply connected to the tubing used for applying volume injection into the eye providing thereby a direct IOP value.

To perform the volume injection while measuring IOP with the TonoVET and the second system, the eye was attached on a specific vertical plate (Fig. 7). Eyes were held with crocodile clips on conjonctive tissue to properly maintain the eye but minimize pressures on the eye, which could affect the eye IOP artificially. The sensor activation and its 
information were monitored by an antenna placed above the eye and connected to an impedance analyzer (Agilent, HP 4396B). This configuration enabled us to obtain in parallel the eye IOP and the sensor measurements, while increasing IOP by step volume injections (Fig.7).

To generate a model as close as possible to the IOP increase observed in glaucomatous patients, we tested various solution injection sites to generate this IOP increase. Our preliminary experiments indicated that the increases were different when the solution was injected either in the anterior or in the posterior chamber. Furthermore, the stability of this IOP increase over time was also highly influenced by this injection site. For these experiments, the solution was injected by $50 \mu \mathrm{L}$ step in $12.5 \mathrm{~s}(4 \mu \mathrm{L} / \mathrm{s})$ up to a $500 \mu \mathrm{L}$ final volume. The model was firstly characterized by measuring the IOP increase with the TonoVET and the second pressure measurement system so that the two measures could be compared for future experiments with the lens sensor. Figure $8 \mathrm{~A}$ illustrates the timedependence evolution of IOP changes following a $50 \mu \mathrm{L}$ injection in the anterior chamber above the corneal angle or in the posterior chamber at the ora serrata. It clearly shows that the anterior chamber generated a smaller and more stable IOP increase. Indeed, when the solution is injected into the posterior chamber, the IOP value can decrease by $25 \%$.after 1 minute and by $50 \%$ after 5 minutes whereas it only decreased by $15 \%$ after 1 minute and by about $20 \%$ after 5 minutes when the solution was injected in the anterior chamber. The anterior chamber was thus retained as the injection site for the following experiments.

When the IOP measures with the TonoVET were compared to direct measures in the injection system with the second pressure sensor, a good correlation was obtained between these independent measures (Fig. 8B). In these experiments, the IOP was increased by regular $50 \mu \mathrm{L}$ step injections lasting $12.5 \mathrm{~s}(4 \mu \mathrm{L} / \mathrm{s})$. Figure $8 \mathrm{~B}$ illustrates measurements (after 5 minutes) for three eyes, showing small variations around the theoretical correlation line. These results show that IOP increase, measured by the industrial pressure transducer at the injection site, is consistent with the IOP increase measured by corneal rebound with the TonoVET reference system. This experimental design is now used to characterize how the lens sensor measurements are related to the IOP increase.

\section{Discussion}

The aim of our consortium is to develop new lens sensors for measuring IOP increases in glaucomatous patients during $24 \mathrm{~h}$ periods. The present paper is describing the whole system configuration with the lens sensor, its continuous monitoring and data recording. In addition, we have illustrated how we can generate progressive IOP increases in an isolated pig eye and measure these IOP increases even with the presence of a lens sensor. By contrast to a previous study [12], we preferred injecting the solution in the anterior 
chamber rather than in the posterior chamber because it generated smaller and more stable IOP increases. Furthermore, we have demonstrated that our second pressure measuring system is providing IOP measures nicely correlated to those obtained on the corneal surface by a rebound TonoVET. This good correlation indicates that our in vitro model provides a good glaucoma model because the TonoVET system is relying on the same principles as the classic Goldman system for IOP increase measurements in glaucomatous patients. Therefore, our lens sensor has to similarly establish a good correlation between its measures and IOP measures with our second pressure system. Future experiments will also assess the lens sensor efficacy in vivo because more complex living conditions introduce other parameters such as eye blinking.

The complete measurement chain has also been modeled in order to optimize each contributor. The objective is indeed to provide a soft contact lens, which can satisfy the patient comfort and the economical constraints due to requirement for a disposable device. The consortium integrates needed expertise from wafer process development, RFID, digital signal processing and biological ex-vivo and in-vivo testing. This multidisciplinary expertise increases the likelihood of success in the project execution, which is currently in line with announced objectives.

\section{Acknowledgement}

This work has benefited from the financial support from the French National Research Agency (ANR) in the framework of the TECSAN call for projects. It was also supported by INSERM, Universite Pierre et Marie Curie (Paris VI), CNRS, the Fondation Ophtalmologique A. de Rothschild (Paris), the city of Paris, the Regional Council of Ilede-France.

Conflict of interest

P.A. is a funding partner and employee in Ophtimalia

P.A., G.L., L.R., S.B., S.P., J.S. have filled a patent on the system. 


\section{References}

[1] Hattenhauer MG, Johnson DH, Ing HH, Herman DC, Hodge DO, Yawn BP, Butterfield LC, Gray DT. (1998) The probability of blindness from open-angle glaucoma. Ophthalmology. 105:2099-104.

[2] Leske MC, Wu SY, Hennis A, Honkanen R, Nemesure B (2008) Risk factors for incident open-angle glaucoma: the Barbados Eye Studies. Ophthalmology 115:85-93.

[3] Leske MC, Heijl A, Hussein M, Bengtsson B, Hyman L, Komaroff E (2003) Factors for glaucoma progression and the effect of treatment: the early manifest glaucoma trial. Arch Ophthalmol 121:48-56.

[4] Leske MC (2009) Ocular perfusion pressure and glaucoma: clinical trial and epidemiologic findings. Curr Opin Ophthalmol 20:73-78.

[5] Hughes E, Spry P, Diamond J (2003) 24-Hour monitoring of intraocular pressure in glaucoma management: a retrospective review. J Glaucoma 12:232-236.

[6] De Smedt S, Mermoud A, Schnyder C (2011) 24-hour Intraocular Pressure Fluctuation Monitoring Using an Ocular Telemetry Sensor: Tolerability and Functionality in Healthy Subjects. J Glaucoma

[7] Mansouri K, Shaarawy T (2011) Continuous intraocular pressure monitoring with a wireless ocular telemetry sensor: initial clinical experience in patients with open angle glaucoma. Br J Ophthalmol 95:627-629.

[8] Pajic B, Pajic-Eggspuchler B, Haefliger I (2011) Continuous IOP fluctuation recording in normal tension glaucoma patients. Curr Eye Res 36:1129-1138.

[9] D.Paret. RFID en ultra et super hautes fréquences. Dunod - L'usine Nouvelle ; 2008

[10] François de Dieuleveult, Olivier Romain. Electronique appliquée aux hautes Fréquences. Dunod ;

2008

[11] Continuous Intra Ocular Pressure Measurement Sensor for Glaucoma Diagnostic

Gaëlle Lissorgues, Lionel Rousseau, Patrick Poulichet, Laurie Valbin, Serge Picaud, Laurent Chicaud, Serge Bernard, Philippe Bergonzo, Francois De Dieuleveult, and Philippe Auvray

[12] Wireless contact lens sensor for intraocular pressure monitoring: assessment on enucleated pigeyes; Matteo Leonardi, Elie M. Pitchon, Arnaud Bertsch, Philippe Renaud and Andre Mermoud 
Figure1: Principle of the IOP measurement device. A) The recording configuration. The frame of spectacle contains an electronic circuit to excite the sensor embedded in the contact lens (shown on a finger) placed on the eye cornea by a wireless connection to measure the eye IOP. IOP measurements are achieved at the level of the circuit in the frame of spectacle to be wirelessly transferred to the pocket recorder. B) Data analysis. At the end of the recording period, the IOP measures can be transferred on a computer for interpretation by the ophthalmologist.

Figure 2: Measurement chain showing the overall transfer function

Figure 3: Sensor and eye modeling with contact lens on cornea

Figure 4: Sensor view before integration in soft contact lens (A) and after integration (B)

Figure 5: Coupling coefficient variation "M" under eye movement effect.

Figure 6: Electrical model of the sensor/antenna couple.

Figure 7: Bench IOP measurement on enucleated pig eyes. From left to right one can see the automatic volume injection device, the vertical plate with the pig eye attached with crocodile clips, the TonoVET in front of the vertical plate and finally the Agilent HP4396B showing measurement on its front screen.

Figure 8: IOP measurements in an in vitro model of increase IOP. A) Comparison of IOP variations following injection in the anterior and posterior chambers during the 5 minutes following the injection. B) Correlations between the IOP measurements with a TonoVET ( $\mathrm{x}$ axis) and with the second pressure transducer in the injection tubing system. 


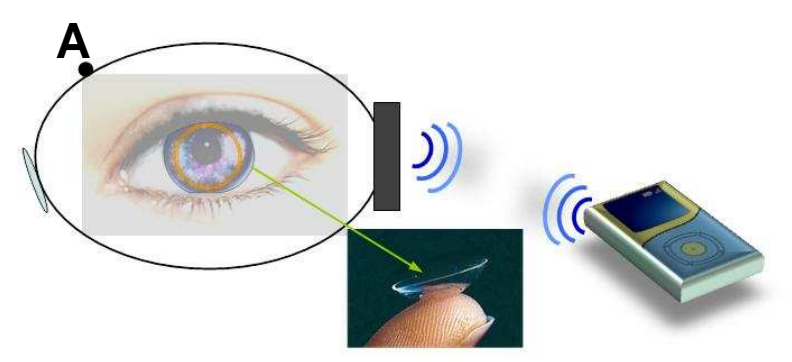

Figure 1

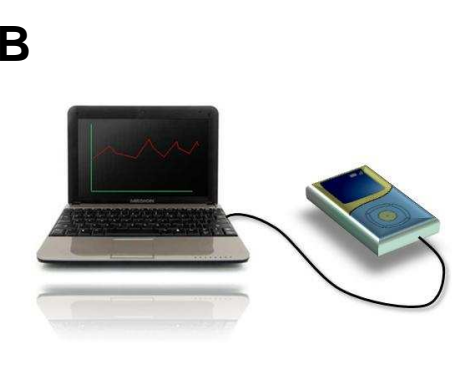

Figure 1

. 


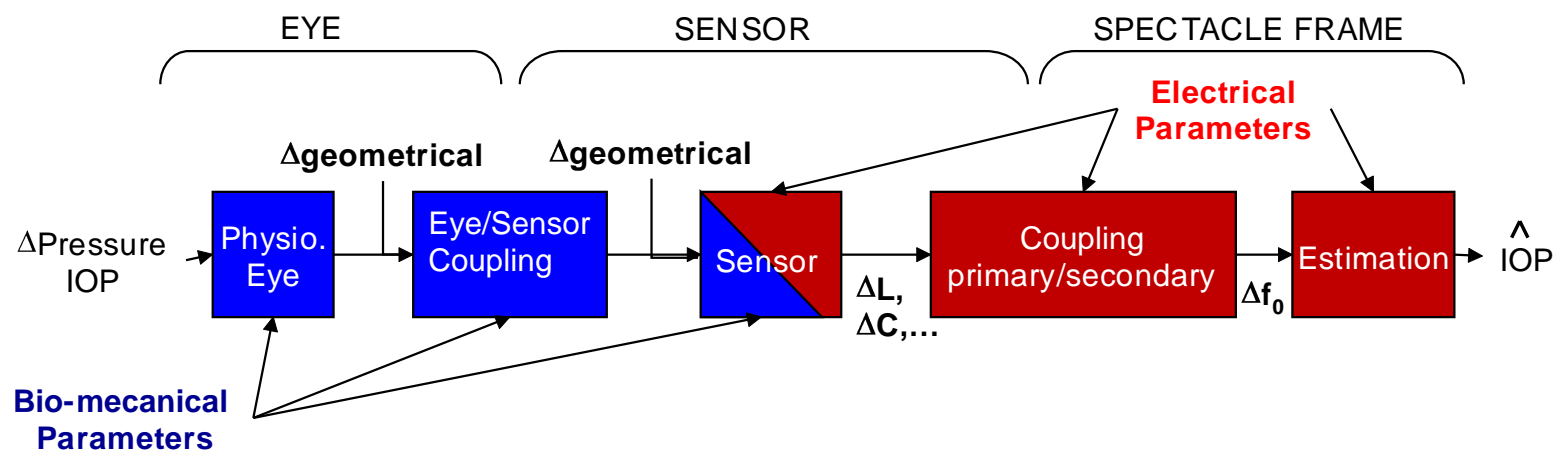




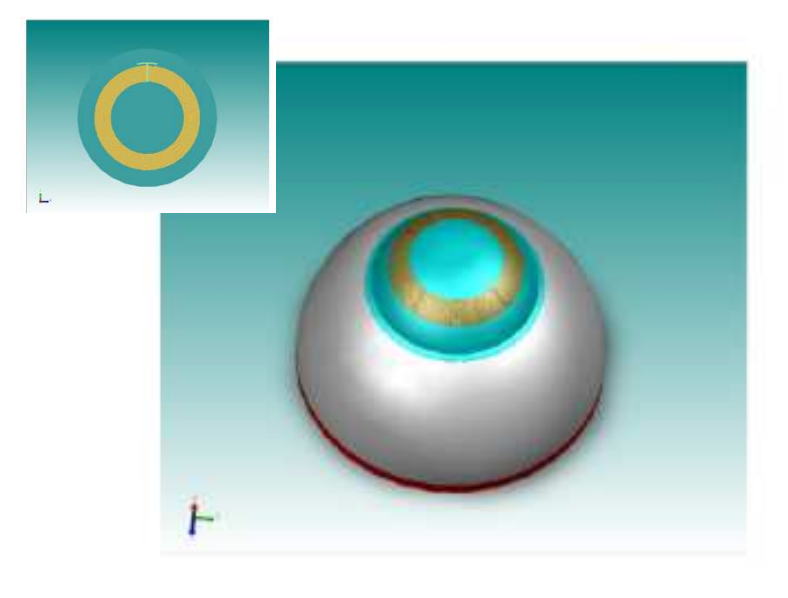

Figure 3

.

Figure

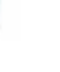




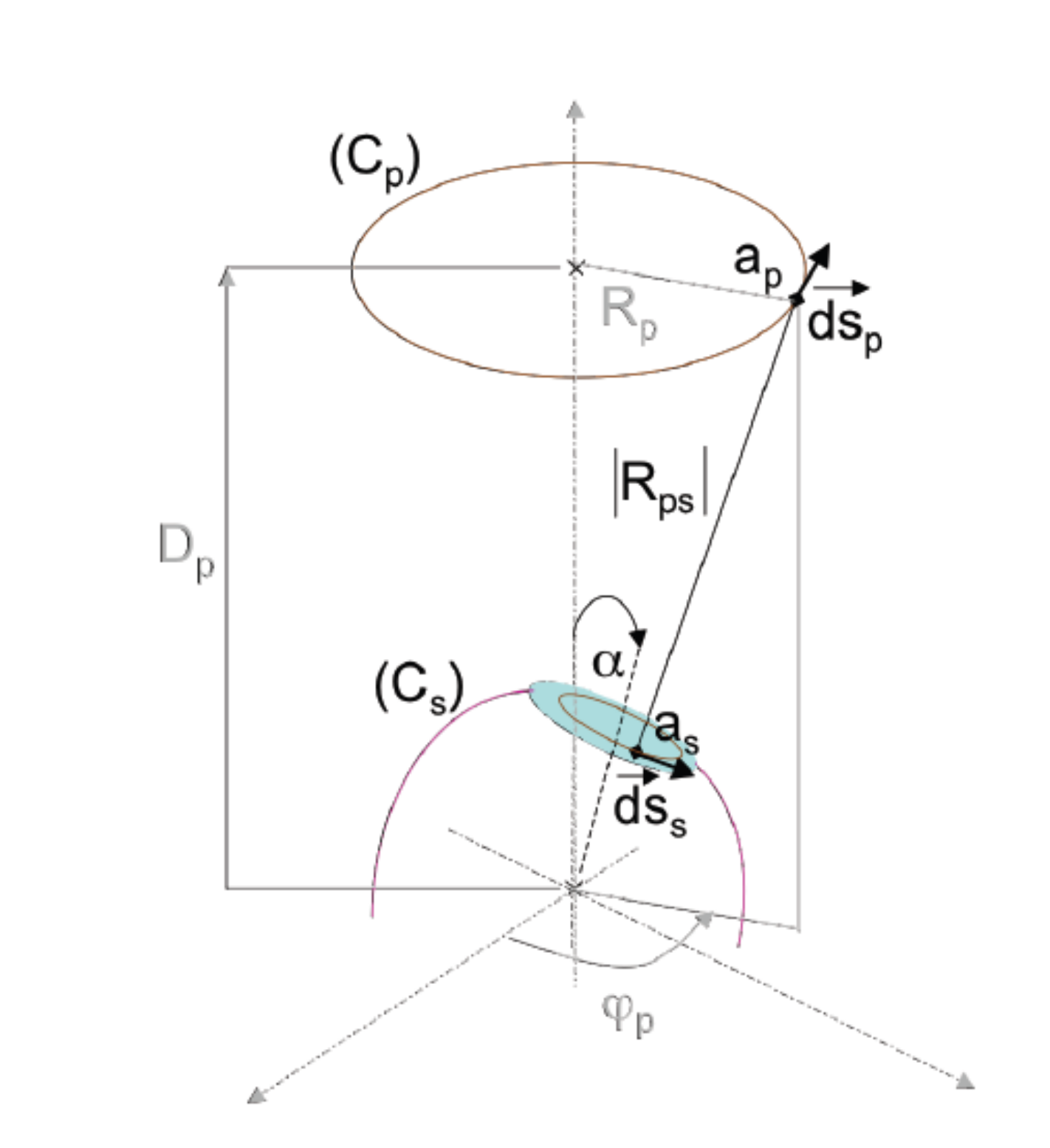

Figure 5

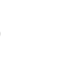
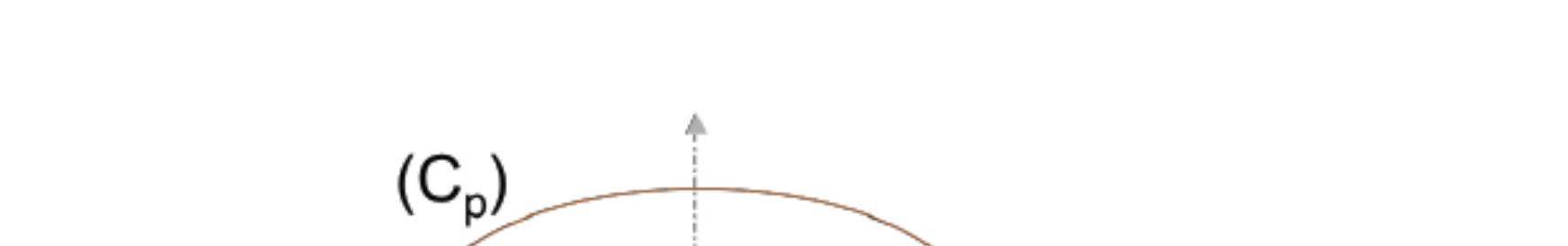

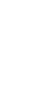
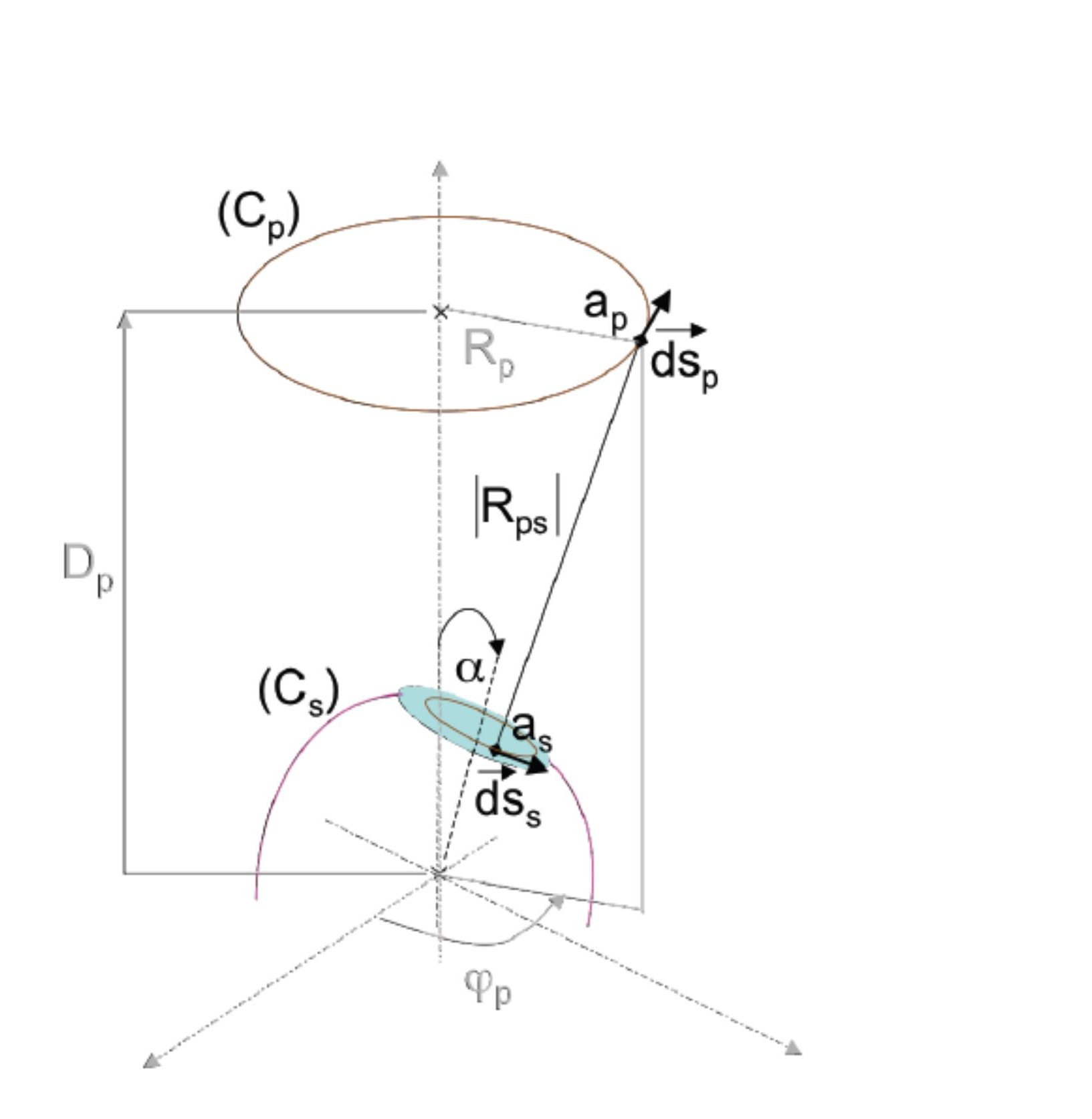


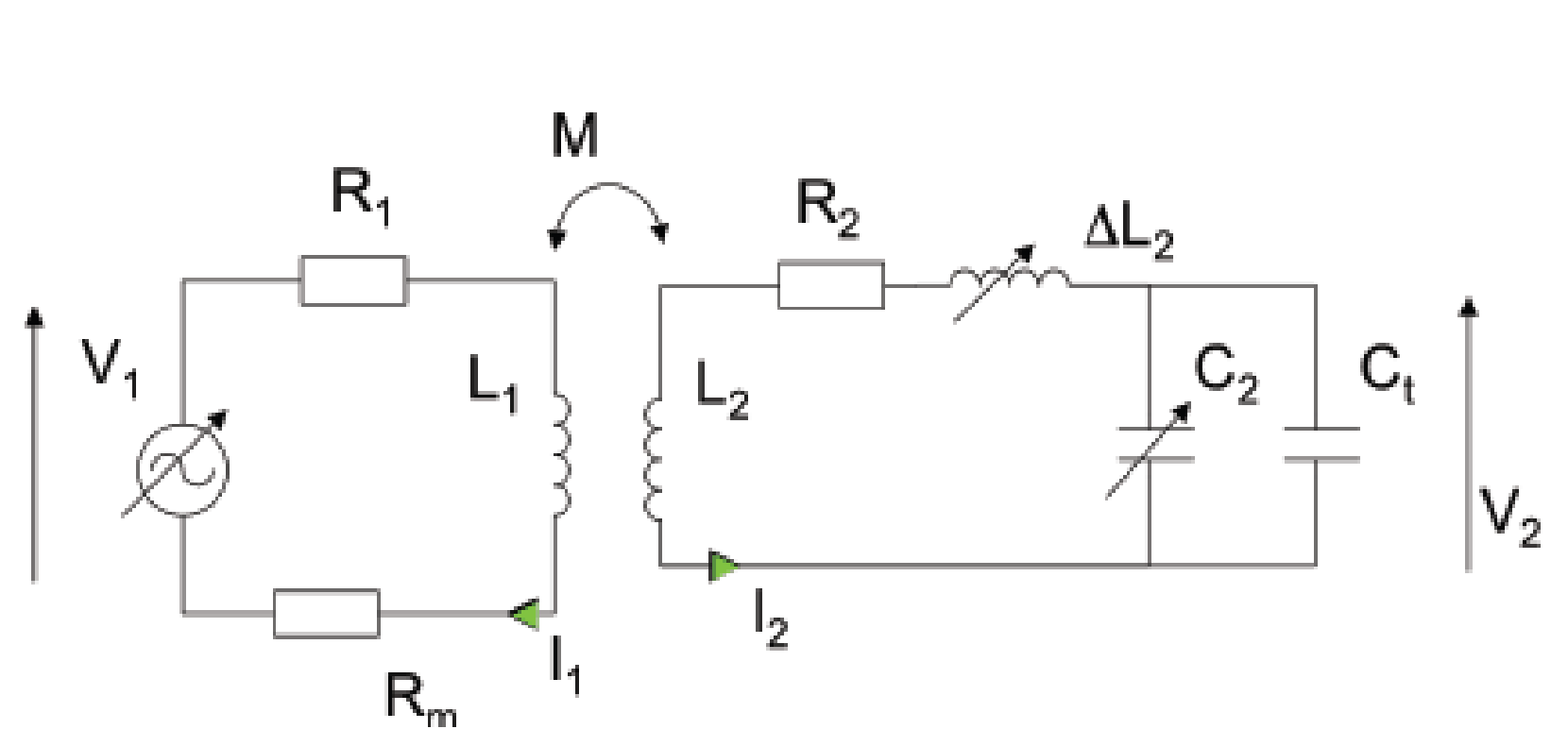

Figure 6

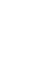
.

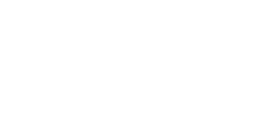

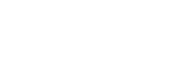

\begin{abstract}
-
\end{abstract}

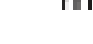

$R_{m}$

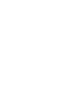

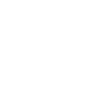

(

.

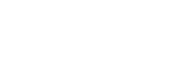


Figure 7
Click here to download high resolution image

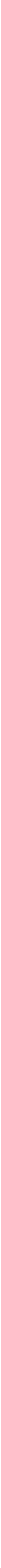

-
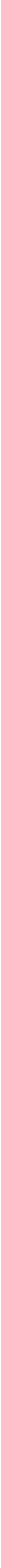
Figure 8
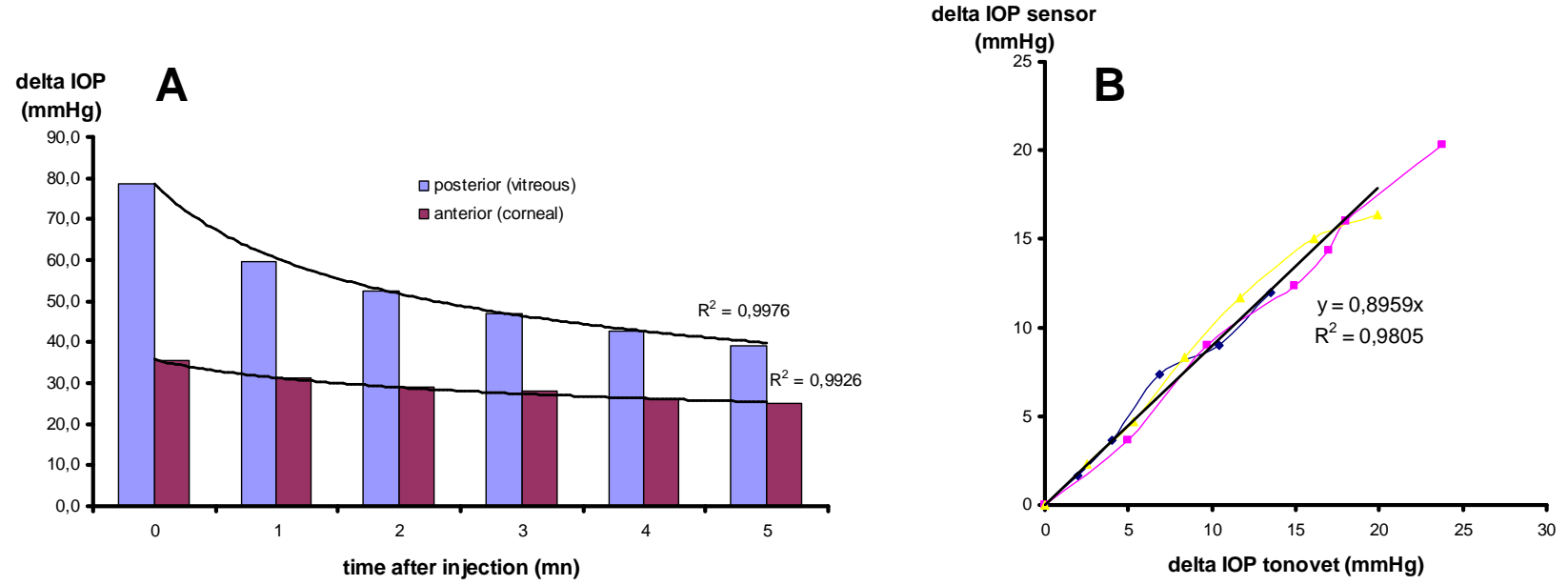